\title{
Online teaching in networked learning communities: A multi-method approach to studying the role of the teacher
}

\author{
MAARTEN DE LAAT ${ }^{1,2, *}$, VIC LALLY ${ }^{3}$, LASSE LIPPONEN ${ }^{4}$ \\ \& ROBERT-JAN SIMONS ${ }^{2}$ \\ ${ }^{1}$ School of Education and Lifelong Learning, University of Exeter, St Luke's Campus, \\ Heavitree Road, Exeter, EXI 2LU, UK, ${ }^{2}$ Centre for ICT in Education IVLOS, \\ University of Utrecht, Utrecht, The Netherlands; ${ }^{3}$ Networked Learning Research \\ Group, University of Sheffield, Sheffield, UK; ${ }^{4}$ Department of Applied Sciences \\ of Education, University of Helsinki, Helsinki, Finland (*Author for \\ correspondence: E-mail:m.f.delaat@exeter.ac.uk)
}

Received: 22 June 2005; accepted: 16 August 2006

\begin{abstract}
The aim of this paper is to study the online teaching styles of two teachers who each tutor a networked learning community (NLC), within the same workshop. The study is undertaking empirical work using a multi-method approach in order to triangulate and contextualise our findings and enrich our understanding of the teacher participation in these NLCs. We apply social network analysis (SNA) to visualise the social structure of the NLC, content analysis (CA) to identify learning and teaching processes, critical event recall (CER) to gather the teacher's personal experiences and intentions. This paper reports some of the current findings of our work and discusses future prospects. This study is part of a continuing international study that is investigating networked collaborative learning as a way to develop a rich descriptive body of evidence of tutoring and learning processes in e-learning.
\end{abstract}

Keywords: computer-mediated-communication, CSCL, learning communities, multimethod, networked learning, online teaching, online tutoring, timeline analysis, triangulation

\section{Introduction}

The aim of this paper is to study the nature of online teaching within a networked learning community (NLC). By networked learning (NL) we mean the use of internet-based information and communication technologies to promote collaborative and co-operative connections: between one learner and other learners; between learners and tutors; between a learning community and its learning resources, so that participants can extend and develop their understanding and 
capabilities in ways that are important to them, and over which they have significant control (Banks et al., 2003, p1). The notion of learning in communities (Lave \& Wenger, 1991) has changed the way we experience teaching and learning in education. The teacher is no longer in full control and learners are actively taking responsibility and starting to coordinate and regulate their own (collaborative) learning (Anderson et al., 2001; De Laat \& Lally, 2004; Jones et al., 2000). While, in educational practice, there is still a strong (and much needed) focus on the role of the teacher; researchers are pointing out a changing teacher-student relationship (Mazzolini \& Maddison, 2003; McConnell, 1999; Rimmershaw, 1999; Vonderwell, 2003). The teacher increasingly becomes a 'guide on the side', which implies that students are stimulated to take active control over their own and collaborative learning processes. This allows them to fulfil their particular learning intentions and needs (Gustafson et al., 2004), and coordinate their learning by agreeing on rules and deadlines (Vonderwell, 2003). It allows students to actively schedule their activities and assign roles within the group, instead of just exploring the content in order to finish their learning task (Hammond \& Wiriyapinit, 2004; Strijbos et al., 2004). As such, every member of this community may be seen as both a learner and a tutor (De Laat \& Lally, 2003). Of course, the designated teacher continues to have a status apart, being responsible for the overall coordination of the workshop and its educational goals. This changing relationship emphasises the need to articulate new pedagogies that require teachers to design and facilitate this more student-oriented approach to learning (Bonk \& Cummings, 1998). After all active participation and control by student over NL activities can lead to tension and frustration in the group. McConnell (2005), for example, showed how strong personalities and failure to reply to requests and questions from other members can frustrate or hinder the collaborative learning experience and the production of a collective product in the end. Hara and Kling (2000) reported that lack of feedback and ambiguous instructions can lead to confusion, anxiety and frustration amongst the students. According to them this was partly due to weaker social cues in the NL environment and misperception by the teacher partly resulted by students' reluctance to express themselves. Insecurity and unfamiliarity with NL can prevent students from active participation because they are not used to being criticised or challenged by other students. Cramphorn (2004) for example showed that unfamiliarity with the constructivist approach to learning creates barriers. Students were not used to posting their own 
thoughts in the early stages of a course and did not realise the fact that they could be seen and criticised by all the other members. According to him it is important that both students and teachers are explicitly informed of the social constructivist nature of NL, to reduce the shock of their own ideas and reflections appearing as transparent to all members of the forums. Students need to develop confidence that they can construct knowledge that is valid and of value (Clouder \& Deepwell, 2004). Establishing a community forum is, by itself, not enough (Ferry et al., 2000). Teaching online requires different, and often new, skills for the teacher, as well as a different attitude towards teaching or being a teacher.

This article is part of a continuing study in NL where the focus is on developing an empirical overview for learning and teaching in NL as a way of informing both theory and praxis (see De Laat, 2006 for a complete overview of this project). This project will enable us to increase our understanding of what is actually happening when participants are engaged in networked teaching and learning activities. In this article we present teachers' experiences with NL, where our previous paper (De Laat et al., 2006) is concerned with the students' experiences and activities while working in the same NLCs. For these two studies we had chosen to explore two NLCs. NLC 1 is assigned to an experienced teacher and NLC 2 involves a teacher who is teaching this course for the first time. The study on students' experiences presented findings of how these two NLCs, were engaged in teaching and learning processes. Content analysis on learning and teaching activities revealed that both groups developed a similar pattern, where most of the activity (both learning and tutoring contributions) is found in the middle phase of the project and in both groups there are a lot of cognitive, metacognitive and facilitative contributions. However participation patterns (based on social network analysis) between the two groups seemed rather different, group one acted more as a stable group throughout, whereas in group two, participation differed from phase to phase, and the involvement the learning task, in particular, was not equally spread among the participants. The second group (based on contextual analysis) worked out an explicit framework of roles and responsibilities, to support their way of working together, suggesting that this group was dealing with a lot with procedural issues.

In this current paper we turn our attention to the role of the online teacher in the previously discussed NLCs. In particular, we are interested in the teachers' behaviour and experiences to describe how 
they develop their online teaching styles to interact with the students in this open learning environment.

\section{Online teaching}

In this section we look at online teaching more closely. First we will discuss some general pedagogical approaches to online teaching found in the literature. Secondly we would like to present some research findings that discuss the role of the teacher in asynchronous networked learning practices, similar to our own research setting.

In the literature there is a growing understanding that teaching online is different from teaching face-to-face and as such needs its own set of pedagogies to guide the online teacher (Goodyear, 2002). Teaching styles developed during face-to-face teaching cannot simply be transferred to an online learning environment and it is important to develop an insight into the complex online teaching processes and strategies to build the necessary skills and competencies to teach online (Harasim et al., 1997; Stephenson, 2001). In general, online teaching activities design, facilitate and direct the cognitive and social process for the purpose of realising personally meaningful and educationally worthwhile learning outcomes (Anderson et al., 2001). As such, this sounds like nothing new, but the way these tasks are embodied and executed in a networked learning environment bids for a re-orientation. Following these three main activities, Goodyear et al. (2001) suggest eight roles of online teaching (see Table 1). Not all of these roles have equal importance and some might not even be used in every situation but in general they describe a wide range of competencies and skills online teachers need. When it comes to the design and organisation of networked learning, Goodyear et al. (2001) suggest that the teacher has to be able to specify the right online learning activities to fit the course needs and have knowledge of the appropriate pedagogies to create and support the online activities. The teacher has to be able to show the relevance between the activities and its desired outcomes, and select the appropriate media accordingly. During the course, the teacher has to be able to manage student enrolment and participation, and use online techniques to monitor learning processes to be able to ensure the authenticity of students' work. To facilitate the networked learning event the teacher needs to demonstrate self-confidence and a willingness to be open. They need to challenge students to participate in networked learning 


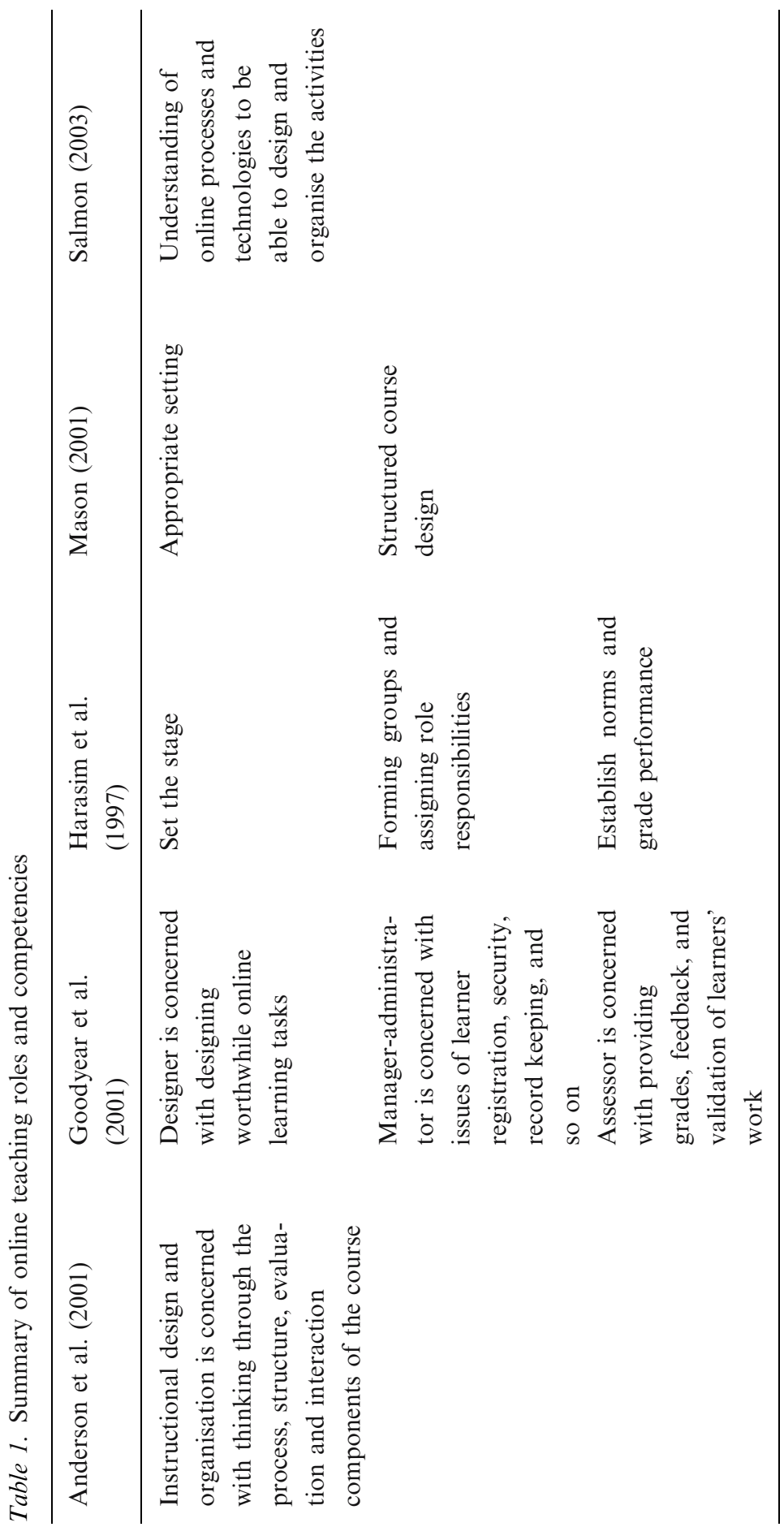




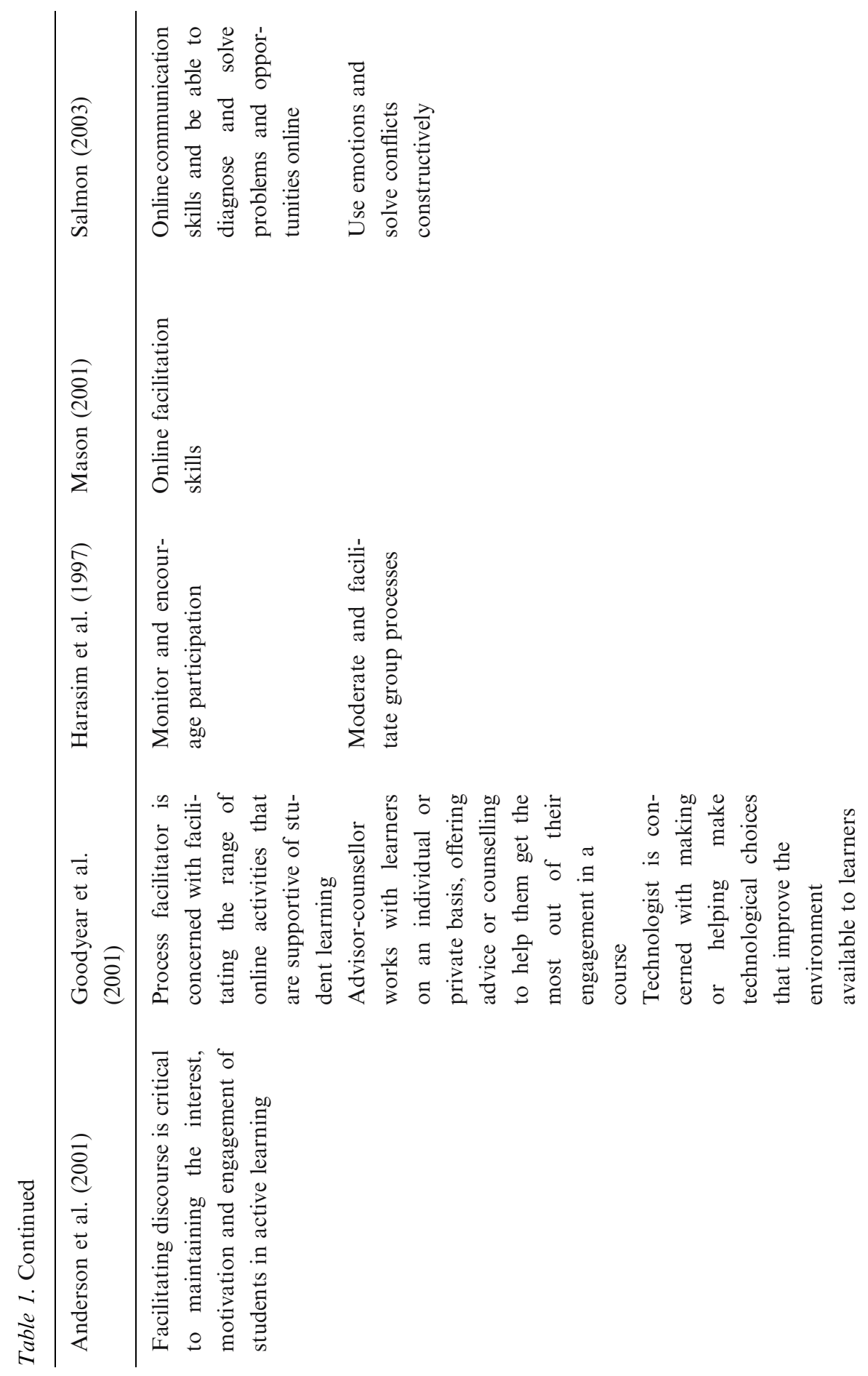




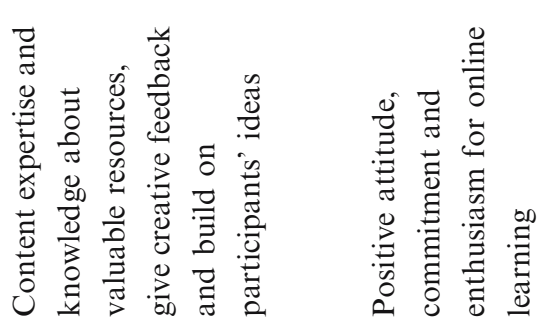

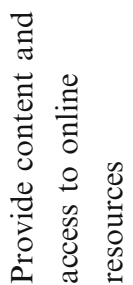
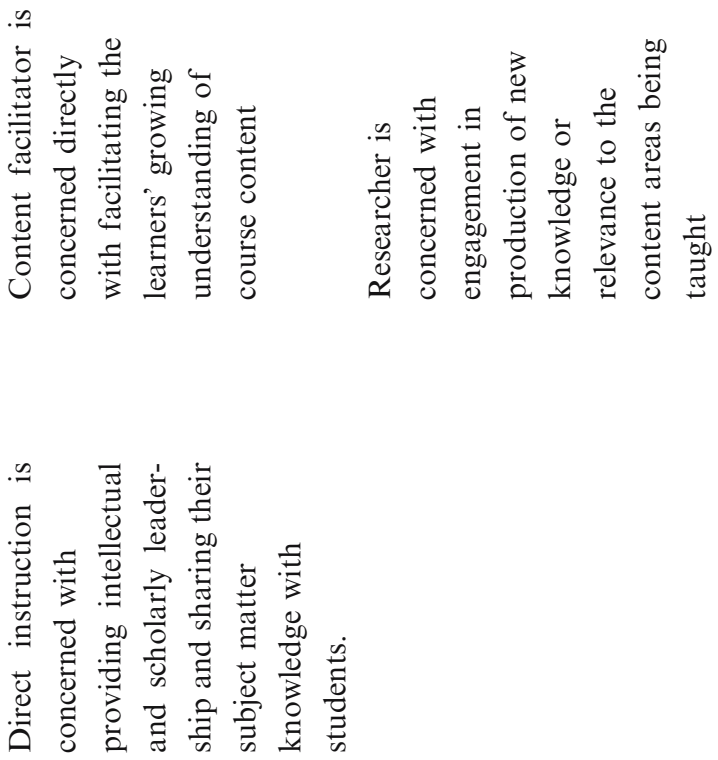
activities, and support them to do so both on an individual basis as well as offer support to the entire group. Here, a certain ambiguity needs to be tolerated. The teacher must help the students articulate their learning concerns and needs in order to make them responsible for their own learning and that of others. This way a student-centered environment can be created and supported, and a sense of community can be established. Working with appropriate group dynamics to support the community is a particular relevant competency. The teacher should help to pace the learning process and reinforce students' contributions. Also, they should make summaries of key points in the discussion and guide the discussion to keep it within the course goals and objectives. This way the teacher can intervene to provide direction, give information, and manage disagreement. The instructional part of online teaching is concerned with providing the appropriate knowledge and resources needed to generate and offer course content. The teacher should therefore also act as a researcher to stay up to date, not only with the development of the subject matter of the course, but also with new teaching models and pedagogies to improve one's own teaching.

Harasim et al. (1997) suggest that an online teacher plans the upcoming activities, follows the flow of the conversation, and offers guidance when needed. The teacher provides a set of group structures that enable students to work out a problem or undertake a task, develop strategies to regulate and coordinate their own (collaborative) learning; and the teacher needs to be present, but play a background role. Typical activities are: setting the stage by developing a warm environment and providing clear directions and support structures; monitoring and encouraging participation by following student activity, making expectations clear and modelling responsiveness; forming groups and assigning role responsibilities using appropriate pedagogical (collaborative) models; moderating and facilitating group processes by coordinating interaction, scheduling and organising the structure of the interaction, providing social and emotional support); and establishing norms and grade performance. Mason (2001) states that for successful facilitation the following categories need to be considered: the setting must be appropriate for online learning; course design needs to be well structured to avoid overload and assist navigation through resources; the teacher needs to develop facilitation skills to be successful online and provide access to extended online resources. Similar competencies are mentioned by Salmon (2003). Teaching online involves having an understanding of online processes 
and technologies to be able to design and organise the activities. The teacher should have online communication skills and be able to diagnose and solve problems and opportunities online, as well as be able to use emotions and solve conflicts constructively. The online teacher should have content expertise and knowledge about valuable resources, give creative feedback and build on participants' ideas. They should also demonstrate a positive attitude, commitment and enthusiasm for online learning.

\section{Research in online teaching}

In general there seems to be a consensus about the online teachers' role and competencies in the literature. It is therefore interesting to discuss some studies in networked learning that focus on the role of the teacher to see if this consensus is reflected in recent empirical studies.

With respect to the teachers' overall presence during networked learning activities, recent studies report that students perceive the communication with the teacher as constructive and encouraging, and they like the tutor to be involved throughout the course and not just at the beginning (Browne, 2003; Clouder \& Deepwell, 2004; Vonderwell, 2003). Also Rimmershaw (1999) concludes that the teacher's active participation might have been critical in setting the right tone for the more successful courses and Rovai (2001) stresses that it is the teacher's challenge to create appropriate conditions by developing a sense of community in the group. According to Lim and Cheah (2003) there are a number of roles that teachers should play during asynchronous learning, these are: setting meaningful tasks; providing technical guidance; participating actively; keeping the discussion focused; drawing conclusions; providing content expertise; and recommending resources for extension of learning. At the same time they argue that teachers need more specific guidelines on how to execute their roles in asynchronous discussion boards. They suggest for example that the teacher should make sure that the discussion is an integral part of the learning activity and not an activity on the side. Similarly, teachers could provide clearer instruction about what messages should contain to avoid lengthy messages with multiple points or arguments. Levy (2003) reports that at the early stages of the course there was a need for more intensive and direct personal contact between teachers and participants, in particular to monitor and support individual participants' awareness of specific features of the 
learning design and more general understanding of learning issues. Ferry et al. (2000) concluded that it is the task of the teacher to set the scene at the beginning of the course, and to keep the conference constructive throughout. Teachers constantly need to monitor the discussion and provide input at appropriate moments (Ferry et al., 2000). At the same time research points out that the students themselves started to develop leadership roles within their group. These roles emerged from the strong feeling that a leader was needed to actively monitor and pull the reins from time to time, and to keep the discussion more focused (Light et al., 2000; Strijbos et al., 2004). However most important is that the teacher needs to tune in-during the collaboration process to find out what kind of moderation behaviour a specific group needs. "The social and pedagogical presence of the instructor is essential for improved communication and learning. Yet, online instructors need to be careful in structuring a feedback mechanism to encourage students inquiry and collaboration rather than a quick, immediate answer to a question that can itself be a barrier for effective student learning." (Vonderwell, 2003, p. 88).

The studies in general seem to support the pedagogical approaches to online teaching as articulated in the presented literature. Research shows that teacher involvement and active participation is appreciated by the students. The students find communication with the teacher constructive and encouraging, and the teacher can support the students by setting the right tone for the discussion and contributing to develop a sense of community. With respect to the roles that teachers should play, the studies point out that in the beginning students seem to need or appreciate active pedagogical guidance from the teacher, which can gradually transform into a more facilitative role in the middle and end stage of the discussion. However a constant monitoring (even if only from a distance) by the teacher throughout is required to be able to tune in when needed. There is some evidence of students picking up some roles or leadership tasks to compensate for the 'lack' or absence of the teacher's input (see for example De Laat \& Lally, 2004; Hammond \& Wiriyapinit, 2004; Light et al., 2000; Vonderwell, 2003).

In this study, it is our aim to explore the teacher's online behaviour. The aim of this paper is to study the online teaching styles of two teachers, who each tutor a NLC, within the same workshop. We will use the empirical data to reflect upon the presented discussion of the research literature and discuss our current understanding of teaching online. 


\section{Methods}

\section{Sample}

The students featured in this analysis are undertaking a Master's Programme in E-Learning (M. Ed.) that is based upon an action research approach to professional development. It is an advanced part-time programme designed to provide participants with opportunities to engage with theory and praxis of networked tutoring and learning. The programme is based upon the establishment of a 'research learning community' among the participants and tutors (see De Laat, 2006; EQUEL position paper, 2004, for a full description on the design principles and structure of this course). Activities are undertaken around five 'workshops' over a 2-year period. The programme is entirely online and hosted in the virtual learning environment WebCT. The students are mainly mid-career professionals, many of whom have post-graduate experience of higher education, are engaged with teaching responsibilities, and often charged with developing e-learning within their own organisation.

In the M.Ed. the students are expected to actively take charge of developing and regulating their learning agenda, guided by a teacher on the course. The networked learning activities are connected to work-related experiences and problems. In this study the data is taken from the first workshop of this programme, where the two NLCs worked on a similar task with the aim to develop a course design for online learning, making use of current learning theories and research findings. We included two NLCs in this study to contrast the online teaching styles. NLC1 consists of seven students and one teacher. NLC2 consists of nine students plus one teacher. We divided the 10-week period into three sections: beginning, middle and end. This allowed us to take a timeline analysis approach. From each period we took a 10-day sample to form our data set. In each sample we analysed messages in selected threads rather than sampling across threads. This was important to enable us to follow and code the development of learning and tutoring within an ongoing discussion rather than across unrelated messages. This resulted in a selection of 235 messages in NLC1 and 215 messages in NLC2.

\section{A multi-method approach}

In order to provide a more holistic and complimentary description of teachers' engagement in NLCs, we developed a multi-method research 
approach and we studied a beginner teacher and an experienced teacher to contrast their teaching styles. In research terms, much is still unclear about the effective forms of NL and there is a need for more empirical descriptive research to provide an evidence-base for the pedagogical processes both teachers and students are engaged in. Hakkinen et al. (2003) suggested a multi-method approach that is process-oriented and takes into account different contextual aspects of NL. They argue that research is needed that captures the process and organisation of collaborative interaction and its contribution to learning:

'Methods should be developed not only for capturing processes and outcomes of learning, but also experienced effects and individual interpretations of participation in CSCL settings.'

(Hakkinen et al., 2003, p. 402)

The aim of this kind of research is to provide a more complete picture of NL processes. We think it is important that this research is focused on the central processes of NL, that is: learning and teaching. We believe that these understandings will contribute to the development of better pedagogical frameworks and software that more effectively support learning and tutoring by design. We have developed a multi-method research framework to study NL processes by making use of social network analysis (SNA) to find out "who is talking to whom', content analysis (CA) through coding teaching and learning activities as a way to find out 'what they are talking about', and context analysis $(\mathrm{C} \times \mathrm{A})$ focusing on the experiences of the participants to find out 'why they are talking as they do' (Figure 1).

These three methods are used to triangulate and contextualise our findings and to stay close or connected to the first-hand experiences of the participants themselves (De Laat, 2006).

To find out who is talking to whom we used SNA to study the way people participated and interacted with each other. This provides information about the activities of such a community and the way they learn collaboratively. WebCT generates log-files through which information about the activity of the members can be obtained. The information retrieved from WebCT can be treated as relational data and stored away in a case-by-case matrix to analyse interaction patterns. For this purpose we focused on the cohesion of the network (Scott, 1991; Wasserman \& Faust, 1997), based on writing and responding to messages. 


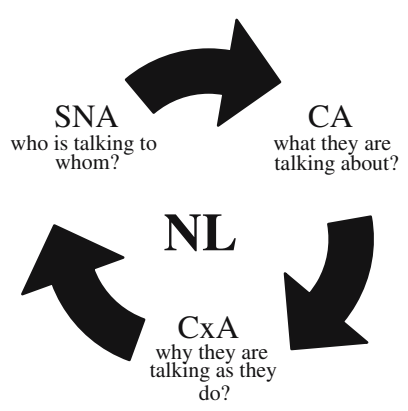

Figure 1. Multi-method research framework for studying networked learning.

To get a first indication of the cohesion of the network we calculated the density of the network. Density is a property of a whole network and describes the general level of linkage among the nodes in a network. The density is at a maximum $(100 \%)$ when all the nodes are connected to each other.

Then we conducted centrality measures to find the central participants within the network. For each participant this has been done using Freeman's degree. Freeman's degree calculates the activity of individual members in the community. With this the network activity of individual members can be indicated. Since we know the nature of the relationship between the participants, i.e., who interacts with whom, we can work with directional relationships. Directed ties, called arcs, specify the orientation of the relationship (Wasserman \& Faust, 1997). This is of special interest for the centrality measures and the creation of the sociograms. In a directed case-by-case matrix, a participant can be either adjacent to, or adjacent from another node, depending on the direction of the arc (Wasserman \& Faust, 1997). This means that we can consider these cases separately by differentiating between in- and outgoing connections. This is done by calculating the in-degree and out-degree centrality measures. In-degree centrality is a form of centrality that counts only those relations with a focal individual reported by other group members, and is therefore not based on self reports as is out-degree centrality (Borgatti et al., 2000). In this study, in-degree measures provide information about the number of people who respond to a message from a certain participant. Out-degree gives an indication of the number of messages a person has sent to other individual members of a network.

UCINET, the program that we used to carry out the analysis, also allows one to make different kinds of visualisations of the relationships within the network. For this study we chose a sociogram 
representing the connections between the participants and its direction in a way that it includes the actual number of ingoing and outgoing messages (Wasserman \& Faust, 1997).

The following step of our analysis was concerned with finding out what they are talking about. The central purpose of CA is to generalise and abstract the complexity of the original messages in order to look for evidence of learning and tutoring activities. In order to probe collaborative NL (learning and tutoring) we 'coded' the contributions using two coding schemas (De Laat \& Lally, 2003).

The first coding schema, developed by Veldhuis-Diermanse (2002), was used to code units of meaning that were regarded as 'on the task', focusing on the learning processes used to carry out the task. This schema includes four main categories: cognitive activities used to process the learning content and to attain learning goals; metacognitive knowledge and metacognitive skills used to regulate the cognitive activities; affective activities, used to cope with feelings occurring during learning, and miscellaneous activities. We decided to exclude miscellaneous category in our analysis since we are interested in the evidence of learning activities. The second schema is used to code units of meaning that are 'around the task', where the focus is on tutoring (Anderson et al., 2001). This schema includes three main sub-categories: design and organisation, facilitation of discourse and direct instruction. Our intention here was to attempt to reveal the ways in which the participants were facilitating and regulating each other's learning, while undertaking the workshop project task.

Codes were assigned to parts of messages based on semantic features such as ideas, argument chains, and topics of discussion (Chi, 1997). Capturing these activities using strict syntactic rules was not possible because of the elaborate nature of a discussion. We chose to use NVivo software to help us to partially automate this process: to highlight segments of the text with coding that we claim represents a particular learning or tutoring activity. In effect, these coded segments were our units of meaning. NVivo was also used to conduct searches of the coded data, in order to produce summary tables (see Tables, below). To determine our inter-coder reliability we firstly, for each coded message, checked to see if the codes assigned by the two coders referred to the same parts of the message (i.e., the same units of meaning). Secondly, we checked to see if the two coders had assigned the same codes to each unit. Based on a $10 \%$ sample of all the messages coded by the two researchers, a Cohen's Kappa of 0.86 was established. 
Content analysis has provided us with evidence of learning and tutoring process patterns that were occurring in this group during the workshop task. To understand these patterns further we need to find out why they are talking as they do. Contextual analysis $(\mathrm{C} \times \mathrm{A})$ can be done using several techniques, like interviews, critical event recall (CER), thinking out loud (TOL), course evaluation forms, student diaries, etc. In this particular study we applied CER using the summary results of the CA and the messages exchanged during the project as a stimulus for CER interviews with the participants. This was done to gain feedback from them about their own understandings of the patterns that emerged, and to help us to understand the context in which these patterns were emerging. The CER interviews enable the articulation of many previously unexpressed aspects of learning and help to contextualise and elucidate individual behaviour, based on personal motives and perceptions in relation to the task and the other participants. Therefore, we pursued those situational and contextual aspects of NL that were identified by participants during these recall interviews. The interview layout contains two parts. The first part is based on stimulated recall of the learning event (CER). During the second half of the session the opportunity for post-hoc reflections was provided, with additional follow-up questions to help probe and understand the group processes. In this paper the results of the CER with the teachers of NLC1 and 2 are reported. The students' CERs are reported in our paper on students' experiences with NL (see De Laat et al., 2006).

\section{Findings}

Firstly we will analyse the findings of the SNA by presenting density, centrality (degree) measures, and interaction patterns, as a way to explore the interactivity of the community members.

The density values of NLC1 and NLC2 show the overall connection between the participants. There seems to be a clear difference between group 1 and 2. First of all, the density values of group 1 are higher, indicating that the participants have more connections amongst each other. Secondly the density values of the first group remain stable throughout the entire project. In group 2, the values remain stable between the beginning and middle phase but in the last period the value drops from $36 \%$ to $26 \%$, indicating that the number of connections between the participants has gone down. Similar density values have been found by other researchers studying network 
learning ties in discussion boards and studying groups of similar size and asynchronous learning settings (De Laat, 2002; Martinez et al., 2003; Palonen \& Hakkarainen, 2000; Reuven et al., 2003). Although $26 \%$ can be considered as rather low for a group of this size.

To have a closer look at participation in these NLCs we present the findings of the in- and out-degree values for each participant (see Tables 2 and 3) and the visual representation of the interaction patterns (see Figures 2-7) for each phase of these NLCs as they emerged from the discussion threads in WebCT. NLC 1 shows a rather even spread contribution by all its members when compared with NLC2. In NLC2 some participants have a high in- and out degree number while participation of other members is either low or seems to go up and down at various stages of the project. Amani seem to be the consistent participant in this group, Monique seems to get heavily involved in the middle phase while Alan's participation seems to increase as the project develops (Table 4).

Table 2. Density values for NLC1 and NLC2 in the beginning, middle and ending phases of workshop 1

\begin{tabular}{llll}
\hline Density & Beginning & Middle & End \\
\hline NLC1 & 0.46 & 0.48 & 0.48 \\
NLC2 & 0.34 & 0.36 & 0.26 \\
\hline
\end{tabular}

Table 3. Out- and in-degree centrality measures of the participants in the three phase samples for NLC1, workshop 1

\begin{tabular}{lcccccccc}
\hline & Brian* & Ryan & Mary & Danton & Anka & Aimi & Neem & Mort \\
\hline $\begin{array}{l}\text { Beginning phase sample } \\
\text { Out-degree }\end{array}$ & 9 & 87 messages $)$ & & & & & \\
In-degree & 9 & 12 & 8 & 7 & 14 & 7 & 3 & 0 \\
Middle phase sample & $(91$ messages $)$ & & & & & & \\
Out-degree & 5 & 15 & 18 & 11 & 14 & 14 & 11 & 3 \\
In-degree & 2 & 16 & 20 & 12 & 12 & 14 & 13 & 2 \\
Ending phase sample & $(87$ messages $)$ & & & & & \\
Out-degree & 7 & 6 & 13 & 3 & 26 & 24 & 5 & 3 \\
In-degree & 3 & 3 & 13 & 3 & 24 & 26 & 11 & 4 \\
\hline
\end{tabular}

Note: Pseudonyms are used here and in the rest of this paper. A * symbol denotes the university-designated tutor in all tables and figures. 


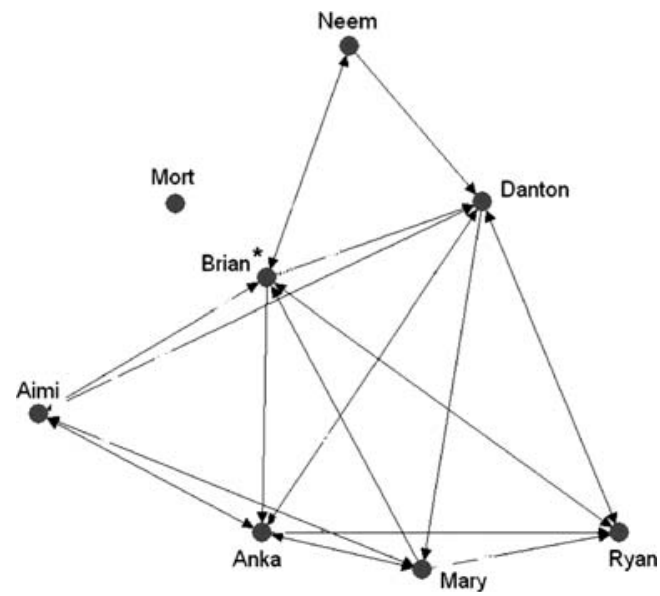

Figure 2. NLC 1, interaction patterns of beginning phase.

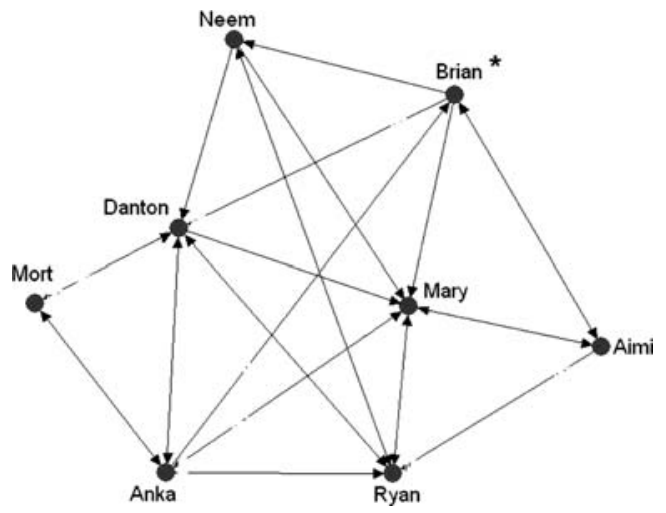

Figure 3. NLC 1, interaction patterns of middle phase.

The presented numbers on their participation will now be used to further interpret the interaction patterns between the participants of both NLCs. Overall we notice that within NLC1 the participants, including the teacher, are acting as one group over the entire period (see Figures 2-4). In the beginning there is only one participant who is not engaging, but this changes in the middle and ending phase of their collaboration. Everybody is involved in the communication and there are no sub-groups or cliques being formed. The teacher has, in the beginning phase (Figure 2), a somewhat central position, although this is not a dominant one. Together with Danton and Anka they are the most connected and central participants in this phase. 


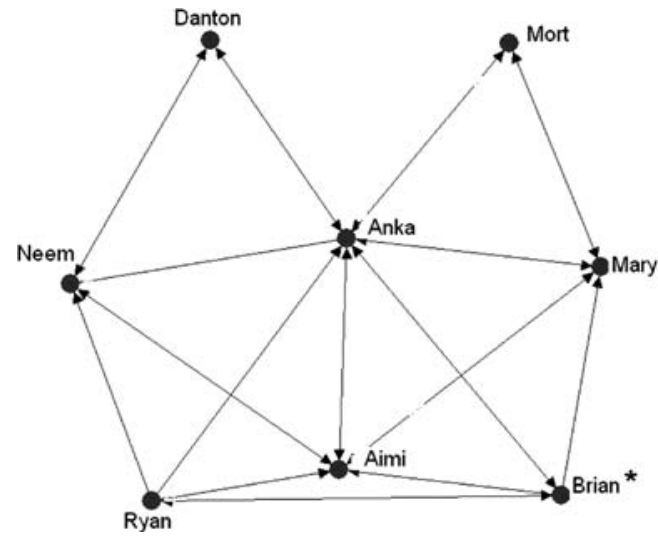

Figure 4. NLC 1, interaction patterns of end phase.

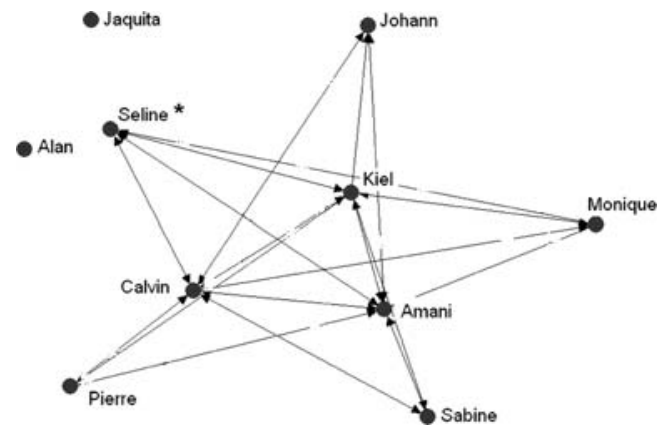

Figure 5. NLC 2, interaction patterns of beginning phase.

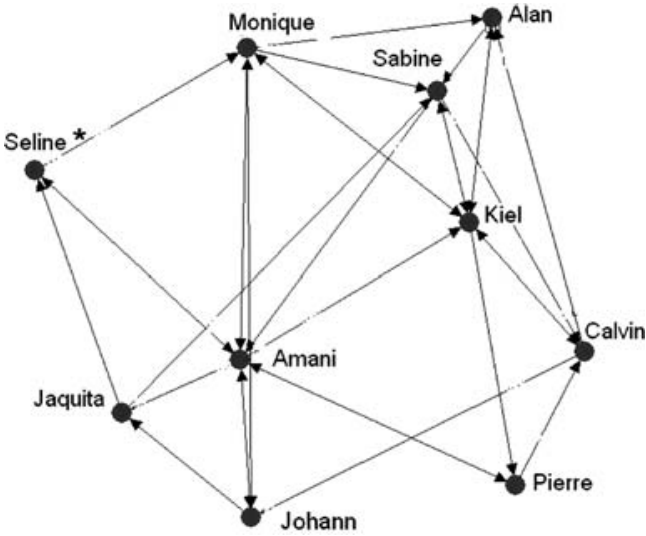

Figure 6. NLC 2, interaction patterns of middle phase. 


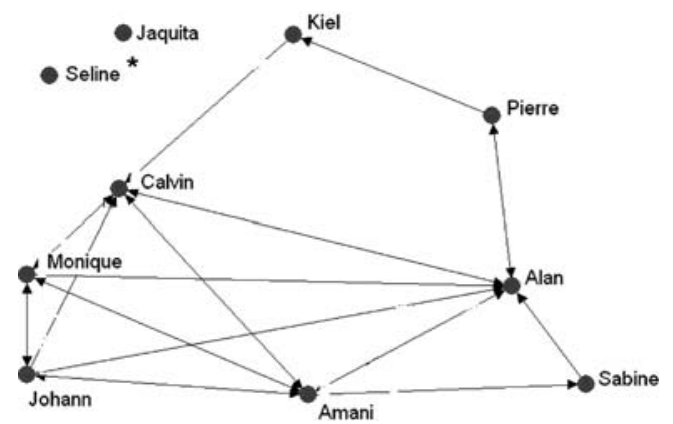

Figure 7. NLC 2, interaction patterns of end phase.

Table 4. Out- and in-degree centrality measures of the participants in the three phase samples for NLC2, Workshop 1

Seline* Sabine Calvin Monique Pierre Amani Johan Kiel Jaquita Alan

\begin{tabular}{|c|c|c|c|c|c|c|c|c|c|}
\hline \multicolumn{10}{|c|}{ Beginning phase sample (59 messages) } \\
\hline Out-degree 6 & 5 & 13 & 8 & 4 & 10 & 6 & 7 & 0 & 0 \\
\hline In-degree 6 & 5 & 14 & 2 & 2 & 16 & 6 & 8 & 0 & 0 \\
\hline \multicolumn{10}{|c|}{ Middle phase sample (94 messages) } \\
\hline Out-degree 2 & 5 & 4 & 20 & 2 & 41 & 7 & 8 & 2 & 3 \\
\hline In-degree 2 & 8 & 4 & 19 & 2 & 37 & 8 & 9 & 2 & 3 \\
\hline \multicolumn{10}{|c|}{ Ending phase sample (62 messages) } \\
\hline Out-degree 0 & 2 & 14 & 8 & 2 & 15 & 11 & 1 & 0 & 9 \\
\hline In-degree & 2 & 11 & 7 & 2 & 15 & 11 & 1 & 0 & 13 \\
\hline
\end{tabular}

This dynamic has somewhat changed in the middle phase where the teacher has moved more towards the side (periphery), while Mary (who was more peripheral in the beginning) moved to the centre of the NLC, making active contributions to the groups task. Danton is also still quite active and Anka has moved more to the side as well.

In the last phase of their 10-week collaboration, the group structure has changed again. There appears to be less connection between all the participants, and all the communication seems to be focused around Anka (and Aimi) to some extent. The teacher is still making contributions to the conversation from the sidelines.

Now that we know more about the individual in- and out-degree measures and interactions patterns of this NLC, we can start to look at their teaching and learning activities (see Table 5). This table reflects the tutoring and learning activities that all the participants were engaged in while writing their messages to the group. The changing teacher-student relationship (as mentioned before) is quite 
Table 5. NLC 1 case summaries of learning and tutoring processes for each of the phases

\begin{tabular}{llllllllll}
\hline NLC 1 & Brian* & Ryan & Mary & Danton & Anka & Aimi & Neem & Mort & Total \\
\hline $\begin{array}{l}\text { Beginning } \\
\text { (57 messages) }\end{array}$ & & & & & & & \\
Learning & 9 & 3 & 12 & 10 & 12 & 3 & 3 & 0 & 52 \\
Tutoring & 27 & 19 & 25 & 6 & 35 & 21 & 4 & 0 & 137 \\
Middle (91 messages) & & & & & & & \\
Learning & 0 & 35 & 35 & 13 & 26 & 19 & 26 & 8 & 162 \\
Tutoring & 18 & 26 & 25 & 6 & 16 & 16 & 27 & 8 & 142 \\
End (87 messages) & & & & & & & & \\
Learning & 3 & 4 & 9 & 1 & 11 & 11 & 0 & 4 & 44 \\
Tutoring & 11 & 9 & 9 & 3 & 22 & 27 & 5 & 5 & 91 \\
\hline
\end{tabular}

visible, since we can now see that all the participants, including the teacher, are covering both learning and tutoring statements. The teacher's style is to act as a learner, which might suggest he is trying to participate in this community on an equal basis. The teacher's involvement reduces somewhat in the middle and ending phase (as was supported by the SNA findings) and is concentrated on tutoring. This is most noticeable in the middle phase where the group is making a large number of contributions to their collaborative task. It is interesting to see for example that in the beginning Mary makes a large contribution to both tutoring and learning, even though in the SNA pattern (see Figure 2) she did not appear as a central person. This might mean that she wrote large messages touching on a number of issues at once. Danton seems to be more focused on learning processes throughout the 10-week period, while Anka is involved in both.

Based on this information we held a CER interview with the teacher to reflect on his tutoring style:

"My teaching style is to let the group be emergent in their learning and let them seek their own rhythms and ways of working and learning together. But at the same time being present in the workshop by giving subtle advice or hints in a certain direction or just keeping a close watch over the group's movements without interfering but being ready to do so whenever I felt necessary."

This quote illustrates the teacher's competency and confidence in teaching online. From the literature, discussed earlier, teacher presence was concluded to be important, without being dominant. In this case the teacher is closely tuned in with the group's activities while 
encouraging them to develop a group structure to support their collaborative learning processes:

"I put in an advanced organiser in the spirit of Ausubel by giving them two headings. One is to organise the process and one is to identify a project. However, the group did not really bother with the process at this stage, they were only interested in the content. But I was trying to pre-organise it a bit. I might have been to early basically. But my concern was to flag up these two issues or concerns I had.

The teacher clearly acts as a process facilitator, but as the next quotes show, does not hesitate to facilitate the content when needed.

"They had lots of good and interesting ideas. But I was aware of the increasing complexitity of their project. And I wanted to sound a note of caution by saying, keep it do-able."

He saw himself as modest moderator within this group, making extensive use of his previous experiences through which he has built up an understanding of online teaching and learning processes:

"I felt very comfortable throughout this workshop because of my experience. I knew the kind of mental framework that I was going to go through, I knew the kind of pitfalls they might go down and I knew the rabbit holes that might appear as well."

"I was making this sort of architectural framework through my messages, that was either going to be directive or taken up, or points that I can point back to and say, 'now I have made this framework and over there you see that door, or window, or arch or whatever', that can be supportive once they realize these points themselves."

He felt, because of previous experiences, that he has a deep knowledge of the dynamics around this workshop and that he kind of knows what the groups will go through and what to expect as a result of that:

"Obviously no group is the same and there are differences and problems but to have a general understanding and a mental framework helps me to create some scaffolding, and knowing how they operate in and around that helps me to pull them back if necessary. Sometimes they don't need it and they are fine on their own. 
This CER interview illustrates how the teacher felt during this workshop and explains his intention to act moderately (avoiding a central position) and let the learning emerge by supporting the group but also by acting as a learner and not being too directive in his tutoring style.

In NLC2 (with the starting teacher), we see some similarities in the teacher appearance in the sociograms (Figures 5-7). This teacher also remains peripherally active, however at the end, there is no involvement any more. In the beginning period the teacher is most active and reduces her involvement thereafter. This NLC, overall, seems in the beginning to be directed by three central participants and as a whole is not operating as one group. This is indicated by the star shape (see Figure 5). This shape changes later on where the shape becomes more like a circle suggesting a more equal participation of all the members.

Also, in the middle phase the teacher still seems to be on the sideline of the overall interaction. This is indicated by the limited connections with the participants in this NLC. Most of the group activity is on the right side of this figure and 'disconnected' from the teacher's direct engagement. Amani and Kiel are still the central participants, Calvin has moved more towards the side.

At the end phase the teacher has made no active contribution to the NLC. Amani and Calvin together with Alan are the most active members, and Kiel made a marginal contribution in this stage.

The coding summaries for NLC2 (Table 6) suggest a mixed (learning and tutoring) involvement from the teacher, and it seems that both Amani (tutoring $=33$ ) and Calvin (tutoring $=25$ ) are regulating and coordinating most of the discussion. During the middle phase the teacher involvement has reduced and became more focused on tutoring. In this phase, Monique started to contribute quite extensively, as well as Amani, but Sabine appeared less central in the SNA pattern when compared to Amani (see Figure 6). Kiel, interestingly, shows almost the opposite tendency, making relatively small learning and tutoring contributions, but still taking a central position in the SNA pattern (see Figure 6). In the end phase the teacher made no active contribution to the NLC discussion.

During the CER we asked the teacher about the tutoring style and engagement in this NLC. She started by saying she recalled one student being very dominant and this overwhelmed her and made her uncertain about her capability to facilitate this NLC. This led to participate very marginally (see case summaries in Table 6). 
Table 6. NLC 2 case summaries of learning and tutoring processes for each of the phases

\begin{tabular}{|c|c|c|c|c|c|c|c|c|c|c|}
\hline \multicolumn{11}{|c|}{ Beginning (59 messages) } \\
\hline Learning 2 & 19 & 17 & 13 & 8 & 14 & 0 & 3 & 0 & 0 & 76 \\
\hline Tutoring 16 & 12 & 25 & 14 & 4 & 33 & 5 & 9 & 0 & 0 & 118 \\
\hline \multicolumn{11}{|c|}{ Middle (94 messages) } \\
\hline Learning 0 & 6 & 1 & 32 & 0 & 73 & 6 & 12 & 9 & 1 & 140 \\
\hline Tutoring 4 & 12 & 5 & 48 & 5 & 100 & 6 & 14 & 12 & 4 & 210 \\
\hline \multicolumn{11}{|c|}{ End (62 messages) } \\
\hline Learning 0 & 0 & 11 & 12 & 0 & 21 & 4 & 0 & 0 & 5 & 53 \\
\hline Tutoring 0 & 6 & 16 & 17 & 4 & 19 & 14 & 4 & 0 & 10 & 90 \\
\hline
\end{tabular}

"One of the students was very dominant and had a very strong online presence, and had a very combating and critical tone in his messages towards me and gave me, at one stage, a major crisis. This made me realise that I had to be there at a certain stage but I wasn't, and I over-reacted to that especially when I realised that it wasn't such an issue for the other students. It was just coming from him."

Once she reflected on the messages and when she went through them again, she realised she had more impact on the group than she initially thought:

"My feeling of the students of this workshop has stemmed from the fact that this is my first time as a tutor, and even though I know a lot about e-learning I found it a challenging experience and unnerving at many times. And I am now [during the $3^{\text {rd }}$ workshop] getting near the stage of feeling comfortable about it, because now I am beginning to get the evidence and the feedback that some of the contributions that I have made have been worthwhile and I am seeing some student achievement there, despite my occasional shortcomings or my perceived shortcomings."

This comment shows that also teachers can feel uncomfortable with NL and that getting familiar with it over time helps them to build up the confidence and experiences needed to act as a competent online teacher. During the third workshop she feels she is getting close to understanding the online processes of this particular course. The teacher reflects on the lessons learned from this experience: 
"I felt overwhelmed by the complexity of the postings, raising so many issues that, well if I have to reply to all of that, it is going to take me so many hours and I don't have the time. I am afraid that my strategy was that I did not respond because I felt I didn't know what to do. I was wondering about my role, when it is learned, led and emergent learning, well how does the tutor facilitate that and move it on, because there are too many issues there to address all of them. So at times, I did not respond because I felt I did not have the skills and the know how to do that."

Reflecting on this experience she realises now that...:

"It is partly self-belief and partly the identity of how I communicate. The path I found was to comment in a gentle and constructive way and to touch on some issues rather than all of them and make a summarising remark to the other issues. It feels like a kind of balancing act."

Her comments (similar to the experienced teacher) show that teachers over time develop their own teaching style and build a pedagogical framework of the course their teaching. This helps them to feel confident to balance between providing structure or allow the groups to be emergent in their learning.

\section{General discussion and conclusions}

One of the main findings of this study is the picture it paints of online teaching as a rich and delicate undertaking, where the teacher is balancing between creating a climate of openness and using pedagogical experience to create supportive structures for learning, supporting the teaching styles mentioned during the introduction. It requires a lot of trust and sensitivity, on the part of the teacher, not to interfere with the activities of the learner immediately; it seems to help to build in (throughout the work) a kind of subtle support framework for the group. Learners can use this to work more independently as they progress.

It is clear from our findings that the experienced tutor:

- Allowed the group be emergent in their learning

- Allowed the participants to seek their own rhythms and ways of working together

- Kept a close watch on the group without interfering, but being ready to assist 
- Used advanced organisers to build a pedagogical framework for participants to use when they are ready

- Had a general understanding and a pedagogical framework of this particular course that he used to create specific scaffolding in particular contexts.

From our analysis of the beginner tutor's experiences it is clear that:

- She was challenged and unnerved by the complexity of the task at times

- She was unsure how to deal with some common specific problems such as one of the students being very dominant and critical of her tutoring

- She did not anticipate the need to clarify the expectation that students should have of her at an early stage

- She felt overwhelmed by the complexity of the postings, raising so many issues

- She was unclear about her role, and how to facilitate and move the group on (at times she did not respond because she felt she did not have the skills and the know-how to do that).

The issue of the beginner teacher is also referred to by Goodyear et al. (2001). One of the suggestions he makes to help novice online teachers deal with these potential complexities is to offer a larger framework within which the making of individual design decisions, or other pedagogical commitments, can be understood and located (a process of which the experienced teacher, Brian was clearly aware). The novice teacher needs to be supported and introduced in the larger pedagogical scheme of things. Part of the expertise of an effective online teacher is the ability to draw on a repertoire of such tactics, with the flexibility required to implement a variety of strategies. But an equally important part of this expertise is to be able to think longitudinally through the levels of the kind of pedagogical framework (Table 1) and the group dynamics portrayed in Figures 2-4. This allows teachers to participate in a joined-up process of educational design and see the connections between the highest level values and beliefs and the minutiae of moment-by-moment online teaching. Bonk et al. (2001) have concluded that in complex learning environments the teacher is vital to any success and certainly cannot hide. Successful online tutors provide frequent feedback on student work, ongoing discussions, reflections and case scenarios. Among the social activities the teacher must be flexible in pressing situations and give some choice regarding assignments. With respect to the managerial role, it 
is important to provide the students with ways to find out the assignment structure and associated due dates, and to spell out the requirements and expectations. In this particular study we have seen differences in teachers' presence throughout the course and their reasons for it. The experienced teacher had a presence throughout and was following the groups activity very closely, building in supportive scaffolds at various points. We also saw that this group had a higher and more equally spread participation rate as well as more stable connections between all its participants. These are two interesting emerging findings and further research is needed to study this potential relationship.

Despite the varied pedagogical approaches used in NL one of the main outcomes of the studies we discussed, and the research presented here, is that there are tensions between the roles of tutors and the roles and responsibilities of students. A key challenge arising from this is how can tutors escape from their traditional roles and give room for new learning? How can tutors gradually scaffold their leadership in a process-oriented approach? How should their role be constructed in the various stages of development of an NL community? The answers to these questions will require further carefully constructed multi-method research that focuses on the complexities of online learning and tutoring processes. A framework for a pedagogy for online teaching might also include support for dialogue and group regulation skills of the learners in NLCs, both to provide feedback on task performance, and to help to develop personal identity in a community of learners. One approach is to make learner experiences explicit not just at the end of the course but at various stages throughout it. This has less to do with conceptual learning and more to do with modelling the role, the language of the learner (Mayes, 2001) and gradually handing over teaching responsibilities to the learners. The presented data of this study clearly shows that both the teacher and students are engaging with tutoring responsibilities. Students are not only regulating their own learning but are also concerned with the group regulation of NL. We feel these findings indicate the importance of applying a multi-method approach to contextualise and relate these findings as a way to develop a context of understanding the complexity of NL. A context that should not only be available to researchers, NLCs should be provided (and create this themselves) with feedback on SNA, CA and $\mathrm{C} \times \mathrm{A}$ repeatedly during their activity as a way to reflect more strategically on their performance and make decisions on how to move forward. 
Early research in NL was focused mostly on the overall processes or outcomes of participant or teacher behaviour, using coding schemes (Gunawardena et al., 1997; Henri, 1992), questionnaires or student feedback (McAteer et al., 1997). More recently there has been articulated a need for a mixed-method approach - sometimes with a preference for a combination of quantitative and qualitative approaches (Hakkinen et al., 2003; Hammond \& Wiriyapinit, 2004; Strijbos et al., 2004). However one aspect that has been largely ignored in NL research is the dimension of time. By focusing on the overall experience or processes of learning and teaching we are in danger of losing the development of this NL experience or how these learning and teaching processes evolve over time, out of sight. Conducting timeline analysis, in this case by describing the beginning, middle and ending phase of NL activities is a way to address this. This research shows that (1) when describing processes it is important to take into account that these processes are not static throughout time but have different dynamics at various stages of the collaborative work. More detailed knowledge of this process helps researchers and teachers (or moderators) develop more refined models for support of NL, and (2) a multimethod approach is not only a way of taking multiple perspectives but also a way of contextualising and building up an understanding of the activities that participants are engaged in, by using the outcomes of one method to further understand the results of next method. This way a more complete understanding of the NL activities can be developed.

\section{References}

Anderson, T., Rourke, L., Garrison, D.R. \& Archer, W. (2001). Assessing teaching presence in a computer conference context. Journal of Asynchronous Learning Networks 5(2): 1-17.

Banks, S., Goodyear, P., Hodgson, V. \& McConnell, D. (2003). Introduction to the special issue on advances in research on networked learning. Instructional Science 31: $1-6$.

Bonk, C.J. \& Cummings, J.A. (1998). A dozen recommendations for placing the student at the centre of Web-based learning. Educational Media International 35(2): 82-89.

Bonk, C.J., Kirkley, J.R., Hara, N. \& Dennen, N. (2001). Finding the instructor in post-secondary online learning: Pedagogical, social, managerial, and technological locations. In J. Stephenson, eds, Teaching and Learning Online: New Pedagogies for New Technologies, pp. 76-97. Kogan Page: London.

Borgatti, S.P., Everett, M.G. \& Freeman, L.C. (2000). Ucinet 5.0 (Version 5.4) [windows]. Natrick: Analytic technologies.

Browne, E. (2003). Conversations in cyberspace: A study of online learning. Open Learning 18(3): 245-259. 
Chi, M.T.H. (1997). Quantifying qualitative analyses of verbal data: A practical guide. The Journal of the Learning Sciences 6(3): 271-315.

Clouder, L. \& Deepwell, F. (2004). Reflections on unexpected outcomes: Learning from student collaboration in an online discussion forum. In S. Banks, P. Goodyear, C. Jones, V. Lally, D. McConnel \& C. Steeples, eds, Proceedings of the Fourth International Conference on Networked Learning 2004, pp. 429-435. Lancaster University: Lancaster.

Cramphorn, C. (2004). An evaluation of formal and underlying factors influencing student participation within e-learning web discussion forums. In S. Banks, P. Goodyear, C. Jones, V. Lally, D. McConnel \& C. Steeples, eds, Proceedings of the Fourth International Conference on Networked Learning 2004, pp. 417-423. Lancaster University: Lancaster.

De Laat, M.F. (2002). Network and content analysis in an online community discourse. Paper presented at the Networked Learning conference, Sheffield, UK.

De Laat, M.F. (2006). Networked Learning. Police Academy of the Netherlands: Apeldoorn.

De Laat, M.F. \& Lally, V. (2003). Complexity, theory and praxis: Researching collaborative learning and tutoring processes in a networked learning community. Instructional Science 31: 7-39.

De Laat, M.F. \& Lally, V. (2004). It's not so easy: Researching the complexity of emergent participant roles and awareness in asynchronous networked learning discussions. Journal of Computer Assisted Learning 20(3): 165-171.

De Laat, M.F., Lally, V., Lipponen, L. \& Simons, P.R. J. (2006). Analysing student engagement with learning and tutoring activities in networked learning communities: A multi-method approach. International Journal of Web-based Communities 2(4).

EQUEL Position Paper. (2004). Special interest group 3. E-learning communities and collaborative learning: Coordinated by University of Sheffield, UK. In Association with Aalborg University, DK. EU Commission e-learning initiative.

Ferry, B., Kiggins, J., Hoban, G. \& Lockyer, L. (2000). Use of computer-mediated communication to form a knowledge-building community in initial teacher education. Educational Technology \& Society, 3(3), [online journal].

Goodyear, P. (2002). Teaching online. In N. Hativa \& P. Goodyear, eds, Teacher Thinking, Beliefs and Knowledge in Higher Education, pp. 79-101. Kluwer: Dordrecht.

Goodyear, P., Salmon, G., Spector, J.M., Steeples, C. \& Tickner, S. (2001). Competencies for online teaching: A special report. Educational Technology, Research and Development 49(1): 65-72.

Gunawardena, C.N., Lowe, C.A. \& Anderson, T. (1997). Analysis of global online debate and the development of an interaction analysis model for examining social construction of knowledge in computer conferencing. Journal of Educational Computing Research 17(4): 397-431.

Gustafson, J., Hodgson, V., Mann, S. \& Olsen, S. (2004). Towards a methodological approach for the analysis of issues of communication and control in networked e-learning discourse. In S. Banks, P. Goodyear, C. Jones, V. Lally, D. McConnel \& C. Steeples, eds, Proceedings of the Fourth International Conference on Networked Learning 2004, pp. 258-266. Lancaster University: Lancaster.

Hakkinen, P., Jarvela, S. \& Makitalo, K. (2003). Sharing perspectives in virtual interaction: Review of methods of analysis. In B. Wason, S. Ludvigson \& U. Hoppe, 
eds, Designing for Change in Networked Learning. Proceedings of the International Conference on Computer Support for Collaborative Learning 2003, pp.395-404. Dordrecht: Kluwer.

Hammond, M. \& Wiriyapinit, M. (2004). Carrying out research into learning through online discussion: Opportunities and difficulties. In S. Banks, P. Goodyear, C. Jones, V. Lally, D. McConnel \& C. Steeples, eds, Proceedings of the Fourth International Conference on Networked Learning 2004, pp. 456-462. Lancaster University: Lancaster.

Hara, N. \& Kling, R. (2000). Students' distress with a web-based distance education course. Information, Communication and Society 3(4): 557-579.

Harasim, L., Hiltz, S.R., Teles, L. \& Turoff, M. (1997). Learning networks: A field guide to teaching and learning online. Cambridge, MA: MITT Press.

Henri, F. (1992) Computer conferencing and content analysis. In: A. R. Kaye (ed), Collaborative Learning Through Computer Conferencing. London: Springer-Verlag.

Jones, C., Asensio, M. \& Goodyear, P. (2000). Networked learning in higher education: Practitioners' perspectives. Association for Learning Technology Journal 8(2): 18-28.

Lave, J. \& Wenger, E. (1991). Situated Learning: Legitimate Peripheral Participation. Cambridge: Cambridge University Press.

Levy, P. (2003). A methodological framework for practice-based research in networked learning. Instructional Science 31: 87-109.

Light, V., Nesbitt, E., Light, P. \& Burns, J.R. (2000). 'Let's you and me have a little discussion': Computer mediated communication in support of campus-based university courses. Studies in Higher Education 25: 85-96.

Lim, C.P. \& Cheah, P.T. (2003). The role of the tutor in asynchronous discussion boards: A case study of a pre-service teacher course. Educational Media International 40: $33-47$.

Martinez, A., Dimitriadis, Y., Rubia, B., Gomez, E. \& de la Fuente, P. (2003). Combining qualitative evaluation and social network analysis for the study of classroom social interactions. Computers \& Education 41(4): 353-368.

Mason, R. (2001). Effective facilitation of online learning: The Open University experience. In J. Stephenson, eds, Teaching and Learning Online: Pedagogies for New Technologies, pp. 67-75. Kogan Page: London.

Mayes, T. (2001). Learning technology and learning relationships. In J. Stephenson, eds, Teaching and Learning Online: Pedagogies for New Technologies, pp. 16-26. Kogan Page: London.

Mazzolini, M. \& Maddison, S. (2003). Sage, guide, or ghost? The effect of instructor intervention on student participation in online discussion forums. Computers \& Education 40(3): 237-253.

McAteer, E., Tolmie, A., Duffy, C. \& Corbett, J. (1997). Computer mediated communication as a learning resource. Journal of Computer Assisted Learning 13(4): 219-227.

McConnell, D. (1999). Examining a collaborative assessment process in networked lifelong learning. Journal of Computer Assisted Learning 15(3): 232-243.

McConnell, D. (2005). Examining the dynamics of networked e-learning groups and communities. Studies in Higher Education 30(1): 25-42.

Palonen, T. \& Hakkarainen, K. (2000). Patterns of interaction in computer supported learning: A social network analysis. Paper presented at the International Conference of the Learning sciences, Michigan, MI, USA. 
Reuven, A., Zippy, E., Gilad, R. \& Aviva, G. (2003). Network analysis of knowledge construction in asynchronous learning networks. Journal of Asynchronous Learning Networks 7(3): 1-23.

Rimmershaw, R. (1999). Using conferencing to support a culture of collaborative study. Journal of Computer Assisted Learning 15(3): 189-200.

Rovai, A. P. (2001). Classroom community at a distance: A comparative analysis of two ALN based university programs. Internet and Higher Education 4(2):105-118.

Salmon, G. (2003). E-moderating: The key to teaching and learning online. London: Routledge Falmer.

Scott, J. (1991). Social network analysis: A handbook. London: Sage.

Stephenson, J. (2001). Teaching and Learning Online: Pedagogies for New Technologies. London: Kogan Page.

Strijbos, J.W., Martens, R.L., Jochems, W.M.G. \& Broers, N.J. (2004). The effect of functional roles on group efficiency: Using multilevel modeling and content analysis to investigate computer-supported collaboration in small groups. Small Group Research 35(2): 195-229.

Veldhuis-Diermanse, A.E. (2002). CSC Learning?: Participation, learning activities and knowledge construction in computer-supported collaborative learning in higher education. Wageningen: Grafisch Service Centrum Van Gils.

Vonderwell, S. (2003). An examination of asynchronous communication experiences and perspectives of students in an online course: A case study. Internet and Higher Education 6(1): 77-90.

Wasserman, S. \& Faust, K. (1997). Social network analysis: Methods and applications. Cambridge: Cambridge University Press. 